\title{
Densidade tecnológica e o cuidado humanizado em enfermagem: a realidade de dois serviços de saúde
}

| 1 Adeânio Almeida Lima, ${ }^{2}$ Daniele Santos de Jesus, ${ }^{3}$ Tainara Leal Silva I

Resumo: Este estudo procura discutir acerca dos ambientes com alta densidade tecnológica - que apresentam grande concentração de equipamentos e instrumentais médico-hospitalares (tecnologias duras), que trazem consigo os desafios ligados à qualificação, modernização e à necessidade de refletir sobre as modificaçóes que possam ocorrer para o cuidado de enfermagem, de forma a responder à seguinte questão: como se configura o cuidado de enfermagem, tendo em vista a perspectiva da humanização em saúde, em instituiçóes com realidades distintas em termos de densidade tecnológica? A partir desta questáo, o estudo teve como objetivo comparar percepçóes e práticas do cuidado de enfermagem, sob a perspectiva da humanização em saúde, em dois serviços hospitalares que se distinguem por apresentar, respectivamente a seguinte configuração: baixa e alta densidade tecnológica. A coleta de dados foi realizada através de entrevista semiestruturada e observação direta. Os dados foram analisados e distribuídos em três categorias: percepçóes de enfermagem acerca do cuidado humanizado; práticas do cuidado e humanização da assistência e fatores que limitam ou que favorecem o cuidado humanizado de enfermagem. Pôde-se perceber que não é a tecnologia por si só que desumaniza o cuidado, mas principalmente como esta opera nos contextos, institucionais e gerenciais.

> Palavras-chave: avaliação de tecnologias em saúde; densidade tecnológica; humanização da assistência; cuidado de enfermagem.

\author{
1 Faculdade Regional a Bahia \\ Salvador-BA, Brasil (adeaniolima@ \\ gmail.com). \\ ORCID: 0000-0003-1171-8299. \\ ${ }^{2}$ Faculdade Regional a Bahia. \\ Salvador-BA, Brasil (xpresthox@ \\ yahoo.com.br). \\ ORCID: 0000-0001-8288-1259. \\ ${ }^{3}$ Faculdade Regional a Bahia. \\ Salvador-BA, Brasil (prestho@ \\ yahoo.com.br) \\ ORCID: 0000-0002-9986-3353.
}

Recebido em: 14/10/2017 Revisado em: 09/06/2018 Aprovado em: 22/06/2018 


\section{Introdução}

As inovaçóes tecnológicas e o desenvolvimento da ciência e da tecnologia influenciam diretamente e cada vez mais a vida em sociedade, gerando, consequentemente, transformaçôes na área da saúde, no meio ambiente, no comportamento dos cidadãos e na vida social. O campo da saúde, em geral, é altamente profícuo quanto a oportunidades para o desenvolvimento científico e tecnológico associadas à produção e utilização de bens e serviços, públicos e privados.

A primeira revoluçáo técnico-científica pode ser situada entre o final do século XVIII e o início do século XIX, cujas transformações tiveram o mérito de substituir, na produção, a força física do homem pela energia das máquinas, primeiramente pelo vapor e, após, pela eletricidade. A tecnologia nessa época passa a ser compreendida como o estudo ou a atividade da utilização de teorias, métodos e processos científicos, para solução de problemas técnicos (NIETSCHE et al., 1999).

Atualmente, o conceito de tecnologia é compreendido de forma ampliada: representada por máquinas e aparelhos (tecnologia dura), saber profissional que pode ser estruturado e protocolizado (tecnologia leve-dura) e a tecnologia leve, que se refere à cumplicidade, à responsabilização e ao vínculo manifestados na relação entre paciente e trabalhador de saúde (CASATE; CORRÊA, 2005).

A tecnologia em saúde, objeto deste estudo, é definida como toda forma de conhecimento que pode ser utilizada para resolver ou atenuar os problemas de saúde de indivíduos ou comunidades (BRASIL, 2006). De acordo com a definição dada pelo Serviço Nacional de Saúde da Inglaterra (NHS) (2006), trata-se de qualquer intervenção usada para promoção, prevenção, diagnóstico ou tratamento de doenças, ou para promover reabilitação ou cuidados de longo prazo. Assim, como exemplo de tecnologias em saúde, temos os medicamentos, equipamentos, procedimentos e os sistemas organizacionais e de suporte dentro dos quais os cuidados com a saúde são oferecidos.

A humanização da assistência, dentro desse contexto, torna-se complexa, já que os recursos tecnológicos aumentam cada vez mais, podendo dificultar as relaçôes humanas, de forma a propiciar a supremacia da técnica sobre o aspecto afetivo situacional, caracterizando uma abordagem tecnicista, o que facilitaria o esquecimento de que está se cuidando de pessoas (FERREIRA, 2007). 
Nesse contexto, os profissionais de enfermagem, como um grupo profissional expressivo do setor, tanto quantitativamente, quanto na sua importância e participação nos processos na área de saúde, sofrem direta e cotidianamente o impacto desse descompasso, principalmente porque o discurso de abordagem humanística da profissão centra-se sobre o cuidado, enfocando o cuidado humano na interaçáo estabelecida entre o profissional (que cuida) e o paciente que participa desse cuidado (ARONE; CUNHA, 2007).

O processo de cuidar está diretamente relacionado a uma ação que ocorre entre dois ou mais indivíduos, gerando, direta ou indiretamente, algum tipo de relação interpessoal. Ele abrange diversos aspectos cotidianos, tornando possível uma dinâmica de troca entre o cuidador e a pessoa que recebe o cuidado, estabelecendo assim uma experiência recíproca. Portanto, o ato de cuidar envolve uma ação interativa, visando à melhoria do estado físico do indivíduo, sua integridade moral, sua dignidade e sua individualidade enquanto pessoa (SOUZA et al., 2006).

Em serviços de maior densidade tecnológica, como é o caso das UTIs, o enfermeiro depara-se constantemente com a necessária e difícil tarefa de harmonizar as tecnologias e a interação mais próxima do paciente. A existência de tecnologias duras pode, assim, colocar em risco a construção do espaço do cuidado humanizado pela equipe de enfermagem, já que, pelo fato de haver possibilidade de monitoramento contínuo e menor contato e relação com o paciente, os profissionais podem deixar de lado as relaçóes interpessoais e a percepção de que outro ser encontra-se sob sua responsabilidade, aspectos primordiais na dimensão do cuidado humanizado.

Trata-se, neste estudo, da análise das práticas de cuidado de enfermagem no ambiente hospitalar, comparando contextos assistenciais de menor e maior densidade tecnológica (como o ambiente da UTI, em que a tensão entre procedimentos tecnológicos e práticas de cuidado oferece evidências importantes para investigação).

$\mathrm{O}$ estudo se justifica pela necessidade de se avaliar em que medida a densidade tecnológica incide sobre o cuidado de enfermagem prestado ao paciente e as associaçóes entre o uso dessas tecnologias e o cuidado desumanizado, de modo a diminuir o descompasso entre estas duas instâncias e apontar elementos que possam melhorar a qualidade da assistência e do cuidado de enfermagem. 


\section{Metodologia}

Trata-se de pesquisa de abordagem qualitativa, tipo estudo de caso múltiplo. A escolha por essa abordagem se deu pela possibilidade que ela oferece de responder a questóes muito particulares, pois ela se preocupa com um nível de realidade que não pode ser quantificado. Ou seja, ela trabalha com o universo de significados, motivos, aspiraçôes, crenças, valores e atitudes, o que corresponde a um espaço mais profundo das relaçóes, dos processos e dos fenômenos que não podem ser reduzidos à operacionalização de variáveis (MINAYO, 2008).

O estudo de caso múltiplo é a seleção de dois ou mais casos, de forma a investigar um fenômeno contemporâneo dentro de seu contexto da vida real, especificamente, quando os limites entre o fenômeno e o contexto não estáo claramente definidos (YIN, 2005), podendo, assim, proporcionar evidências de contextos diferentes, auxiliar na elaboração de uma pesquisa de melhor qualidade (GIL, 2009) e aumentar substancialmente os benefícios analíticos e suas evidências (YIN, 2005).

\section{Caracterização dos casos}

A pesquisa foi realizada nos municípios de Inhambupe e Salvador, respectivamente em duas unidades hospitalares, que foram definidas como casos deste estudo. A opção por esses hospitais foi baseada nos critérios de melhor acesso e adequação aos parâmetros avaliados. Um critério básico para tipificar a densidade tecnológica das duas instituiçôes selecionadas foi a existência ou não de monitores multiparamétricos na unidade. A descrição geral dos casos é trazida a seguir:

Caso 1 - O Hospital Antônio Carlos Magalhães (HACM), hospital com baixa densidade tecnológica. Instituição filantrópica desde 1971 e que, em 2009, passou à esfera pública. Possui atendimento nas áreas de obstetrícia, centro cirúrgico e patologia clínica. É um hospital de pequeno porte, que conta com quatro enfermeiros e 18 técnicos de enfermagem, tendo 13 leitos de observação e 50 leitos de internação, com estrutura mínima para atendimentos a urgências e emergências. Realiza ainda partos, pequenas cirurgias e internamentos de menor complexidade nas clínicas médica, cirúrgica, obstétrica e pediátrica (SESAB, s.d.).

Caso 2 - O Hospital do Subúrbio (HS), hospital com alta densidade tecnológica. Inaugurado em 13 de setembro de 2010, com 268 leitos. Na terapia intensiva são disponibilizados dez leitos de UTI pediátrica e 50 leitos para adultos, com quadro 
geral de 22 enfermeiros e 44 técnicos de enfermagem. O hospital conta com centro de bioimagem, raios $\mathrm{X}$, tomógrafo, ultrassonografia, ressonância magnética, endoscopia e eletrocardiograma. Além de laboratório, central de material esterilizado, farmácia centralizada, serviço de engenharia clínica, fisioterapia, nutrição, dietética e apoio logístico (SESAB, s.d.).

\section{Participantes do estudo}

Foram os profissionais de enfermagem - técnicos e enfermeiros - que atuam nas unidades assistenciais (Caso 1) e Unidades de Terapia Intensiva (UTI) (Caso 2), objetivando alcançar depoimentos que conduzam ao esclarecimento e tomada de consciência da situação problema da pesquisa.

O número de entrevistados não foi definido previamente, uma vez que, por ser um estudo qualitativo, a "amostragem" estava subordinada à saturação das respostas dos entrevistados, pois segundo Minayo (2008), “nesse tipo de estudo a amostragem boa é aquela que possibilita abranger a totalidade do problema investigado em suas múltiplas dimensões".

\section{Coleta de dados}

A coleta de dados foi realizada por meio de duas técnicas: entrevista semiestruturada e observação direta.

A entrevista semiestruturada, segundo Minayo (2008), é aquela que contém como técnica de coleta de dados perguntas norteadoras previamente formuladas, permitindo que o informante aborde o tema livremente segundo um recorte feito pelo entrevistador. Pela possibilidade de alcançar a máxima abrangência na descrição, explicação e análise do problema em estudo, proporciona aos entrevistados todas as perspectivas possíveis de responder aos questionamentos básicos com liberdade e espontaneidade, no sentido de obter dados subjetivos, colocando-se em relação aos valores, atitudes e opiniōes dos participantes entrevistados (TRIVIÑOS, 1987).

$\mathrm{Na}$ observaçáo direta, o investigador não interage com o objeto do estudo no momento em que realiza a observação, logo não poderá ser considerado participante. Este tipo de técnica reduz substancialmente a interferência do observador no observado e permite o uso de instrumentos de registo sem influenciar o objeto do estudo (BOGDAN; BIKLEN, 1994). 
Antes da aplicação definitiva do questionário, foi realizado um pré-teste do instrumento de coleta de dados, a fim de validá-lo e/ou aperfeiçoá-lo. Os respondentes foram questionados acerca das dificuldades, dúvidas ou constrangimentos encontrados durante o preenchimento. Assim, buscou-se verificar, no pré-teste, a percepção dos respondentes quanto à forma e extensão do questionário, bem como quanto à interpretação das questóes, a fim de se certificar de que havia um entendimento comum e correto dos fatores investigados entre os pesquisados, e, ainda, averiguar a opiniáo dos respondentes quanto à importância dos critérios avaliados e sua abrangência.

O pré-teste foi realizado com seis colaboradores da Unidade de Saúde Central da cidade de Acajutiba-BA, no período de 1 a 4 de outubro de 2012. Foram selecionados, para a testagem do instrumento de pesquisa, enfermeiros e técnicos de enfermagem da unidade, buscando o público-alvo do estudo.

A coleta de dados aconteceu no período de 9 a 20 de outubro (Caso 1) e 19 de novembro a 4 de dezembro (Caso 2) de 2012. Como instrumento, foi utilizado roteiro de entrevista semiestruturada, em que constam aspectos ligados à caracterização dos entrevistados (idade, escolaridade etc.), além das questôes norteadoras sobre o estudo em questão. Utilizou-se, ainda, a observação direta e diário de campo para anotaçôes específicas do pesquisador, que registrou as suas observaçôes e intercorrências após cada entrevista ou ao término de cada turno

O tempo estipulado para a aplicação do instrumento foi de, no máximo, vinte minutos, em períodos de até doze horas em campo, período este em que a observação foi realizada. O intervalo de tempo para coleta e saída do pesquisador de cada campo foi de, aproximadamente, duas semanas.

\section{Análise e categorização dos dados}

Os dados foram submetidos a uma análise de conteúdo para que fosse possível compreender o que foi dito ou escrito sobre o tema estudado. A análise de conteúdo, segundo Bardin (2004), é um conjunto de técnicas de análise das comunicaçôes visando obter, por procedimentos sistemáticos e objetivos de descrição do conteúdo das mensagens, indicadores que permitam a inferência de conhecimentos relativos às condições de produção e recepção dessas mensagens. É usada quando se quer ir além dos significados, da leitura simples do real. Aplica-se a tudo que é dito em entrevistas ou depoimentos ou escrito em jornais, livros e textos. A técnica utilizada 
constou das seguintes fases propostas pelo autor: pré-análise, exploração do material e tratamento e interpretação dos resultados.

As entrevistas foram gravadas e, após a coleta de dados, transcritas pelo próprio pesquisador - terminando-se um mês e meio depois de encerrado o trabalho de campo -, permitindo, assim, uma leitura mais fluente. Nesse processo de escutar e escrever, foi possível identificar algumas ideias relevantes que surgiram a partir das falas dos entrevistados. Após a transcrição literal dos dados, passamos à primeira fase, descrita como pré-análise. Nesta etapa, organizamos o material coletado e prosseguimos com a leitura flutuante.

A segunda fase, definida como exploração do material, consistiu na análise detalhada do material selecionado e da codificação dos dados com base nas unidades temáticas, possibilitando uma descrição das características pertinentes ao conteúdo. Organizamos os dados segundo os temas tratados no roteiro da entrevista e segundo as categorias profissionais de ambos os casos.

$\mathrm{Na}$ terceira fase, de tratamento e interpretação, realizamos o agrupamento dos dados em categorias temáticas, tomando como referência a similaridade semântica dos conteúdos proferidos nos discursos.

O processo de categorização consistiu na classificação dos elementos, segundo suas semelhanças e diferenciaçôes, e o reagrupamento em função das características comuns. Analiticamente, as representaçôes que se pretenderam captar puderam ser desdobradas em três categorias: percepçóes de enfermagem acerca do cuidado humanizado; práticas do cuidado e humanização da assistência e fatores que favorecem ou que limitam o cuidado humanizado de enfermagem.

Durante a classificaçáo dos dados, percebemos que os participantes do estudo elaboram e constroem os significados e as explicaçóes através da referência permanente as suas práticas, às responsabilidades deles como profissionais de saúde e à organização de serviços nos quais estão inseridos.

\section{Aspectos éticos da pesquisa}

O projeto foi submetido à análise do Comitê de Ética do Instituto de Saúde Coletiva da Universidade Federal da Bahia e dos hospitais pesquisados, prerrogativa de garantia das normas do Conselho Nacional de Ética em Pesquisa (CONEP), segundo a resoluçáo CNS n 466/12. 


\section{Resultados e discussão}

A partir da observação de campo e do referencial teórico adotado, é possível apontar fatores que possam limitar ou favorecer o cuidado humanizado de enfermagem. De imediato, é interessante ressaltar que tais fatores permaneceram constantes, a despeito da maior ou menor densidade tecnológica do ambiente estudado.

$\mathrm{O}$ perfil dos profissionais de enfermagem do Caso 1 denotou uma equipe jovem, pois variou de 26 a 40 anos; o gênero feminino prevaleceu; quanto ao nível profissional, quinze são técnicos, dos quais três estão em fase inicial do curso da graduação em enfermagem e um iniciou a graduaçáo em serviço social; dos três enfermeiros, dois concluíram cursos de pós-graduação ou especialização (urgência e emergência e obstetrícia). $\mathrm{O}$ tempo de profissáo variou de dez meses a onze anos. $\mathrm{O}$ tempo de trabalho na instituição ficou entre dez meses a oito anos. A carga horária de trabalho, em média, é de seis a sete plantôes mensais de vinte e quatro horas cada.

Já no Caso 2, a equipe é pouco mais jovem, com idade dos profissionais variando entre 21 a 40 anos; em sua maioria, do sexo feminino. Vinte e dois são técnicos de enfermagem, dos quais um está em fase final do curso da graduação em enfermagem; todos os onze enfermeiros concluíram cursos de pós-graduação ou especialização (urgência e emergência; obstetrícia; centro cirúrgico e UTI). O tempo de profissão variou de um a doze anos. O tempo de trabalho na instituição ficou entre um mês a dois anos. A carga horária de trabalho, em média, é quatro a cinco plantóes de vinte e quatro horas cada.

Embora na Instituição 1 o diálogo seja praticado de forma mais ativa pelos profissionais, e açóes como o toque afetivo e terapêutico, a familiaridade com o paciente, a capacidade de estabelecer relaçóes dialógicas esteja mais presente, a Instituição 2 pôde demonstrar maior eficiência técnica, maior distribuição equitativa de tempo, maior capacidade de "manter a sinceridade e a reciprocidade no cuidado", de forma a equilibrar a frágil equação tecnologia versus humanização da assistência.

Os fatores limitantes pareceram estar mais associados à forma com que o profissional fazia uso da tecnologia do que pela presença propriamente desta. $\mathrm{O}$ despreparo profissional para lidar com equipamentos aparece como primeira nuance a ser avaliada, uma vez que pode estimular a insatisfaçáo profissional, a margem de erros e de retrabalho de enfermagem, expondo o paciente a riscos desnecessários e a tratamentos inadequados (BARRA et al., 2006). 
Esta falta de "familiaridade" com o equipamento e a falta de capacitação oferecida, por parte da instituição, para os profissionais poderão propiciar o sentimento de trabalho enquanto "obrigação", aspecto relatado nas falas e que pode, sem sombra de dúvidas, levar ao profissional níveis de insatisfação com suas atividades, desempenhando-as de forma mecanizada, desatenta, pouco afetiva, autolimitada. A insatisfação do profissional de enfermagem com seu trabalho pode fazê-lo sofrer, cansar em demasia ou ainda consumir-lhe todo o tempo que poderia ser usado para o que Castro et al. (2010) chamam de contato verdadeiro, encerrando em si sérias restriçôes ao exercício do cuidado humanizado, já que podem não reconhecer seu trabalho como um meio de exercício da sua identidade enquanto profissional. Poderá, também, prover meios para que o profissional acabe por privilegiar o equipamento, a técnica, em detrimento do paciente, de forma a inverter o objeto do cuidar e transformá-lo em variável secundária do cuidado, como se fora uma extensão da máquina e não a razão de seu funcionamento.

Aspectos diretamente relacionados à presença da tecnologia também puderam ser notados, como exemplo, a presença de ambientes em que os avisos sonoros dos equipamentos são necessários para alertar a equipe acerca de qualquer anormalidade encontrada. Este dispositivo sonoro poderia, segundo os entrevistados, causar estresse não só na equipe, mas, principalmente, nos pacientes, que já se encontram fragilizados em ambiente estranho e, muitas vezes, com perda de sua independência e capacidade de decisão, sendo, assim, levados a ouvir o constante barulho proporcionado por tais alarmes, quer queiram, quer não. Para Cheregatti e Amorin (2010), a existência de inúmeros equipamentos, avisos sonoros, controles rigorosos, aliados ao afastamento da pessoa de seu ambiente podem se constituir em fatores que favoreçam a desumanização do cuidado prestado. A meta da equipe de enfermagem deve ser, portanto e entre muitas outras, maximizar a adaptação do paciente ao ambiente, a partir do conhecimento de seus sentimentos sobre a invasáo de sua privacidade, o que contribuirá para o alcance de maior contato humano nas situaçôes em que a alta tecnologia possa, direta ou indiretamente, interferir no seu bem-estar (LIMA et al., 2010).

Vimos até aqui que, se a exposição à alta densidade tecnológica até possa indiretamente favorecer a supervalorização dos aspectos técnicos em detrimento dos aspectos pessoais, algumas variáveis, como o preparo profissional para lidar com a tecnologia, podem ser mais importantes, do ponto de vista da humanização, que a 
própria presença do aparato tecnológico. Concordamos com Barnard e Sandelowski (2001), quando referem que o que determina se a tecnologia desumaniza, despersonaliza ou objetifica não é a tecnologia propriamente dita, mas sim como as tecnologias individuais operam em contextos específicos do usuário, os significados atribuídos a ela, como qualquer indivíduo ou grupo cultural define o que é humano e o potencial de técnica em enfatizar a eficiência e ordem racional.

A partir deste raciocínio, é possível estabelecer um conjunto de elementos que podem, de acordo com o estudado, apresentar significativa importância na melhoria da humanização. Em primeiro lugar, pôde-se apreender que os equipamentos com alarmes acústicos podem transformar o ambiente num lugar estressante e barulhento, daí a importância de estabelecer um ambiente silencioso ou com som ambiente, de forma a evitar o estresse que o paciente possa ter com tais alarmes, barulhos muito altos, avisos sonoros etc. Este parece, segundo Lima et al. (2010), ser um primeiro passo na busca pela humanização em ambientes com alta densidade tecnológica, de forma a estabelecer um ambiente familiar e acolhedor ao paciente.

Pudemos notar, também, que a melhor distribuiçâo do tempo entre as atividades de enfermagem, de modo a favorecer procedimentos de maior complexidade e não gastar tempo maior que o necessário para a realização de atividades de menor monta, pode trazer um retorno significativo do ponto de vista da humanização, tanto para pacientes quanto para profissionais.

Bedin et al. (2005) afirmam acerca desta observação que rotinas não planejadas muitas vezes não permitem aos profissionais de enfermagem dedicar maior tempo ao paciente e sua família. Relata ainda que, dessa forma, o atendimento dedicado ao paciente se distancia demasiadamente da teoria, já que na prática a atenção individualizada é praticada de maneira mecânica. Assim, a ética profissional que tanto deve ser conservada acaba sendo substituída por práticas adotadas devido à escassez de tempo ou mesmo por comodidade dos profissionais, tornando o ambiente desumano.

Aspectos gerenciais foram também notados, como a possibilidade de instalação de programa de gratificação por desempenho, avaliado a partir das percepçôes dos pacientes e seus familiares, que poderia estimular significativamente a humanização, já que o profissional necessitaria de bom desempenho atribuído para fazer jus à gratificação. Esta concepção até aparece de forma incipiente nas falas dos 
entrevistados, quando relatam que o trabalho prestado acaba sendo a "propaganda" do profissional junto à instituição e ao mercado de trabalho.

Outro aspecto gerencial diz respeito à adequação de horas de trabalho de enfermagem e de pacientes/leito por profissional, de forma a não sobrecarregar os profissionais e comprometer a capacidade laboral dos mesmos e, com isso, a humanização por eles praticada. Esta sobrecarga, imposta pelo cotidiano do trabalho, pode levar a enfermagem a prestar uma assistência mecanizada e tecnicista, não reflexiva, "esquecendo-se de humanizar o cuidado". Os aspectos quantitativos dos profissionais de enfermagem nas instituiçôes de saúde são, portanto, enfatizados para que haja a garantia da segurança e da qualidade de assistência ao cliente e a continuidade da vigília perante a diversidade de atuação nos cuidados e na atenção da equipe de enfermagem (COLLET; ROZENDO, 2003).

O estabelecimento de programas de educação continuada e de capacitaçôes dos profissionais nas unidades também merece destaque, pois, segundo Santo (2003), prepara os profissionais para lidarem com os equipamentos e podem, inclusive, prevenir o efeito da supervalorização da técnica e da máquina sobre o cuidado, já que profissionais que assimilam equipamentos (dos quais dependem diariamente para exercer suas atividades laborais) como acessórios tendem a reconhecer-se enquanto promotores do cuidado, que poderá ou não acontecer mediado pela tecnologia.

\section{Considerações finais}

Não raro, a literatura especializada em Avaliação de Tecnologias em Saúde faz referência à perda, com a introdução de novas tecnologias, de várias ações ligadas ao cuidado humanizado e, entre elas, de uma ação que, de tão simples, passa despercebida pela maioria dos profissionais: "o toque afetivo e terapêutico", da dimensão "Relacional dialógica". Com a suposta "mecanização" e "tecnologização" de atividades corriqueiras, repetitivas e que dispendem muito tempo (e que, regra geral, é um dos grandes motivadores do desenvolvimento de novas tecnologias), haveria, portanto, a diminuição do toque, ainda que simples e tímido, que pode, mesmo involuntário, contribuir em muito para nos sentirmos mais humanos, mais queridos...

Esta perda foi, inclusive, notada na pesquisa, muito mais pela valorização (ou falta desta) dada por alguns profissionais, que propriamente pela presença da tecnologia em si ou diferença significativa do cuidado prestado. É preciso alertar, contudo, 
que esta subvalorização atribuída à prática do "toque afetivo e terapêutico", embora satisfatoriamente executada pelos profissionais, é um indicador que, de fato, a técnica pode estar suplantando aspectos mais sutis, para os quais, embora executados, não é atribuída importância.

Outros velhos problemas e paradigmas do cuidado humanizado ainda coexistem nas instituiçóes, a exemplo do excessivo envolvimento dos enfermeiros com atividades gerenciais, o grande fluxo de pacientes e atividades e, até mesmo, os estigmas históricos que a profissão carrega.

Perceptível também foi a falta de preparo de alguns profissionais ao lidar com o paciente... A informação, aliada ao conhecimento do cuidado humanizado enquanto premissa salutar básica, poderia evitar atitudes e comportamentos de autoritarismo e de visão de "obrigação" do cuidado, transparecida em algumas atitudes e falas observadas.

No geral, o que pôde ser percebido com este estudo, entretanto, é que os profissionais de enfermagem - e o próprio cuidado por estes ofertado - têm se adaptado e evoluído conforme a maior ou menor densidade tecnológica disponível e que, não raro, a humanização está muito mais ligada ao preparo profissional e à consciência da responsabilidade, por parte dos profissionais, de que em suas mãos está um ser vivo pleno de significados - medos, angústias, vivências, temores, crenças - do que propriamente à presença de equipamentos, de tecnologias mais densas.

Esta adaptação se revelou, em ambos os contextos observados, na preocupação em associar atividades menos e mais complexas, ou que exigissem menos e mais contato, por exemplo, de maneira a oferecer mais intimidade e humanização da assistência. Se, por um lado, as tecnologias poderiam diminuir a prática de açóes que poderiam levar à humanização em procedimentos menos complexos; por outro, economiza tempo e a disposição dos profissionais para que realizem de forma mais cuidadosa e prestativa procedimentos de maior monta e que necessitam de maior atenção do profissional. ${ }^{1}$

\section{Referências}

ARONE, E. M.; CUNHA, I. C. K. O. Tecnologia e humanização: desafios gerenciados pelo enfermeiro em prol da integralidade da assistência. Revista Brasileira de Enfermagem. Brasília, v. 60 n. 6, nov./dez. 2007. Disponível em: <http://dx.doi.org/10.1590/S0034-71672007000600019>. Acesso em: 13 dez. 2011. 
BARDIN, L. Análise de Conteúdo. 3 ed. Lisboa: Ediçôes 70, 2004.

BARNARD, A.; SANDELOWSKI, M. Technology and humane nursing care: (in)reconcilable or invented difference? Journal of Advanced Nursing, v. 34, n. 3, p. 367-375, 2001.

BARRA, D. C. C. et al. Evoluçáo histórica e impacto da tecnologia na área da saúde e da enfermagem. Revista Eletrônica de Enfermagem, v. 8, n. 3, p. 422-430, 2006. Disponível em <http://www.fen.ufg.br/revista/revista8_3/v8n3a13.htm>. Acesso em: $13 \mathrm{dez} .2011$.

BEDIN, E.; RIBEIRO, L. B. M.; BARRETO, R. A. S. S. Humanização da assistência de enfermagem em centro cirúrgico. Revista Eletrônica de Enfermagem, v. 7, n. 1, p. 118-127, 2005. Disponível em: <http://www.revistas.ufg.br/index.php/fen>. Acesso em: 19 mar. 2013.

BOGDAN, R.; BIKLEN, S. Investigação Qualitativa em Educação. Porto: Porto Editora, 1994. BRASIL. Ministério da Saúde. Ciência e Tecnologia, 2006. Disponível em: <http://portal.saude. gov.br/portal/saude/visualizar_texto.cfm?idtxt=24684>. Acesso em: 19 ago. 2012.

. Conselho Nacional de Saúde. Resoluçáo n 466, de 12 de dezembro de 2012. Aprova normas regulamentadoras de pesquisas envolvendo seres humanos. Diário Oficial da Uniáo, Brasília, 2013.

CASATE, J. C.; CORRÊA, A. K. Humanização do atendimento em saúde: conhecimento veiculado na literatura brasileira de enfermagem. Rev Latino-Am Enfermagem, v. 13, n. 1, p. 105-11, 2005.

CASTRO, C. A. et al. Dificuldades enfrentadas pelo Enfermeiro na humanização em Unidade de Terapia Intensiva Neonatal. Revista Eletrônica de Enfermagem do Centro de Estudos de Enfermagem e Nutrição [serial on-line], v. 1, n. 1, p. 1-16, jan.-jul. 2010. Disponível em: <http:// www.ceen.com.br/conteudo/downloads/4552_90.pdf?PHPSESSID=7eeef29848fe34fab5bc50 8ac813dce1>. Acesso em: 21 mar. 2013.

CHEREGATTI, A. L.; AMORIN, C. P. Enfermagem em Unidade de Terapia Intensiva. Martinari: São Paulo, 2010.

CONSELHO FEDERAL DE ENFERMAGEM. Resolução COFEN n 189/1996. Brasília: Conselho Federal de Enfermagem. Disponível em: <http://www.portalcofen.com.br/2007/ materias.asp?ArticleID=7121\&sectionID=34>. Acesso em: 15 mar. 2013.

. Resolução COFEN no 293/2004. Brasília: Conselho Federal de Enfermagem. Disponível

em: <http://www.portalcofen.com.br/2007/materias.asp?ArticleID=7121\&sectionID=34>. Acesso em: 15 mar. 2013.

COLLET, N.; ROZENDO, C. A. Humanização e trabalho na enfermagem. Rev Bras Enferm. Brasília, v. 56, n. 2, p. 189-192, mar./abr. 2003.

FERREIRA, A. B. Dicionário Aurélio da Língua Portuguesa. São Paulo, 2007.

GIL, A. C. Estudo de Caso. São Paulo: Atlas, 2009. 
LIMA, S. R.; GUIMARÁES, S. P. de S.; BRASILEIRO, M. E. Pesquisa científica relacionada à análise de fatores estressores para pacientes em Unidade de Terapia Intensiva: uma revisão bibliográfica. Revista Eletrônica de Enfermagem do Centro de Estudos de Enfermagem e Nutrição [serial on-line], 1(1) 1-16, jan.-jul. 2010. Disponível em: <http://www.ceen.com.br/ revistaeletronica>. Acesso em: 2 fev. 2013.

MINAYO, M. C. de S. O desafio do conhecimento: pesquisa qualitativa em saúde. 11. ed. São Paulo: Hucitec, 2008.

NATIONAL HEALTH SERVICE, 2006. Disponível em: <http://www.nhs.uk/>. Acesso em: 19 ago. 2012.

NIETSCHE, E. A.; DIAS, L. P. M.; LEOPARDI, M. T. Tecnologias em Enfermagem: um saber prático? In: SEMINÁRIO NACIONAL DE PESQUISA EM ENFERMAGEM. Anais... maio 1999, Gramado. ABEn-RS: Porto Alegre, 1999.

SANTO, F. H. E. Saberes e fazeres de enfermeiras novatas e veteranas sobre o cuidado de enfermagem no cenário hospitalar. 2003. Tese (Doutorado) - Escola de Enfermagem Anna Nery, UFRJ, Rio de Janeiro, 2003.

SECRETARIA DE SAÚDE DO ESTADO DA BAHIA Hospitais. s.d. Disponível em <http:// www.saude.ba.gov.br/index.php?option $=$ com_content $\& v i e w=$ article $\& i d=182$ : hospitaisdacapit al\&catid=8:estruturadeatendimento\&Itemid=49>. Acesso em: 20 jul. 2012.

SOUZA, S. R. de O. et al. Aplicabilidade de indicador de qualidade subjetivo em Terapia Intensiva. Revista Brasileira de Enfermagem, v. 59, n. 2, p. 201-205, mar. 2006. Disponível em: <http://www.portalbvsenf.eerp.usp.br/scielo.php?script=sci_arttext\&pid =S0034$71672006000200015 \& \operatorname{lng}=$ pt\&nrm=iso>. Acesso em: 13 dez. 2011.

TRIVIÑOS, A. N. S. Introdução à pesquisa em Ciências Sociais: pesquisa qualitativa em educação. São Paulo: Atlas, 1987.

YIN, R. K. Estudo de caso: planejamento e métodos. 3. ed. Porto Alegre: Bookman, 2005.

\section{Nota}

${ }^{1}$ A. A. Lima participou da elaboração e execução do projeto de pesquisa, análise e interpretação dos dados, redação e formatação do artigo. D. R. Souza fez a adaptação ao formato do artigo e redação final. T. L. Silva participou da revisão crítica do conteúdo e aprovação final da versão a ser publicada. 


\section{Abstract}

\section{Technological density and humanized care in nursing: the reality of two health services}

This study discusses the high density technological environments - which present a great concentration of equipment and medical instruments (hard technologies), which bring with it the challenges related to qualification, modernization and the need to reflect on the modifications that may occur to the nursing care, in order to answer the following question: how is nursing care configured, considering the perspective of humanization in health, in institutions with different realities in terms of technological density? From this point of view, the study aimed to compare nursing care perceptions and practices, from the perspective of humanization in health, in two hospital services that are distinguished by presenting, respectively, the following configuration: low and high technological density. Data collection was done through semi-structured interview and direct observation. The data were analyzed and distributed in three categories: nursing perceptions about humanized care; practices of care and humanization of care, and factors that limit or favor humanized nursing care. It could be realized that it is not technology alone that dehumanizes care, but mainly how it operates in institutional and managerial contexts.

Keywords: health technology assessment; technological density; humanization of care; nursing care. 